Pacific Journal of Mathematics

SOUSLIN'S CONJECTURE AS A PROBLEM ON THE REAL
LINE ARNE P. BAARTZ AND GARY GLENN MILLER 


\title{
SOUSLIN'S CONJECTURE AS A PROBLEM ON THE REAL LINE
}

\author{
A. P. BaArtz and G. G. Miller
}

This paper is concerned with properties of real sets whose existence is related to Souslin's conjecture. One of these results is subsequently used to show that Souslin's conjecture is second order determined, i.e., $\left(\mathscr{F} \vdash_{2} S C\right) \vee\left(\mathscr{\digamma} \vdash_{2} \sim S C\right)$.

By Souslin's conjecture (SC) we mean: every linearly ordered set with at most countably many pairwise disjoint intervals is separable. (A linearly ordered set $L$ is separable if it has a countable subset such that between any two points of $L$ there is a point of the subset). We first display a subset of the power set of the real line $R$ whose existence is equivalent to $\sim S C$. Then we reformulate the conjecture geometrically as a question concerning a single subset of $R$ of a certain type. Finally we point out that Souslin's conjecture is second order determined.

E. Miller [4] proved that $\sim S C$ is equivalent to the existence of a Souslin tree, i.e., an uncountable tree of countable height and countable width. A tree is a partially ordered set in which the set of all elements below any given element is a chain. The height of a partially ordered set $P$ is the least cardinal $\mathfrak{m}$ such that no chain in $P$ has cardinality greater than $\mathrm{m}$. A is an antichain if no two elements of $A$ are related. The width of $P$ is the least cardinal $\mathfrak{n}$ such that no antichain in $P$ has cardinality greater than $\mathfrak{n}$.

Proposition 1.1. The existence of a Souslin tree is equivalent to the existence of an uncountable collection of real sets such that

1. any two sets in the collection are either disjoint or one of them is a subset of the other, and

2. if $\mathscr{G}$ is any uncountable subcollection, then $\mathscr{G}$ has two disjoint members and two nondisjoint members.

Proof. Assume there is a Souslin tree $S$. Let $f$ be a one-to-one function from some uncountable subset of $S$ into $R$. For each $x \in S$, let $U(x)=\{y: x \leqq y\}$, and let $\mathscr{F}=\{f(U(x)): x \in S\}$. Then $\mathscr{F}$ has the desired properties.

Conversely, if there is such a collection $\mathscr{F}$, let $A \leqq B$ mean $B \subseteq A$, for $A, B \in \mathscr{F}$. Then $\mathscr{F}$ is a Souslin tree.

An application of Proposition 1.1 is found in $\S 5$. In the next section we show how a Souslin tree can be represented as a single subset of the line. 
2. We first represent certain binary relations. For this purpose let $G \subset R$ and denote by $G^{*}$ the set of all those points $x \in G$ which are midpoints of a nondegenerate segment whose endpoints are both in $G$. We shall call $G^{*}$ the set of midpoints in $G$. Define a relation $\alpha$ on $G^{*}$ by setting

$x \alpha y$ iff $x \neq y$ and there exists $z \in G$ such that $y$ is the midpoint of the segment $x z$.

Note that $x z$ stands for $[x, z]$ or $[z, x]$ according as $x<z$ or $z<x$.

Proposition 2.1. $\alpha$ is a (strict) partial order for $G^{*}$ iff for all elements $x, y, z \in G^{*}$ we have

A. (asymmetry) if $x$ and $y$ are the respective midpoints of $y v$ and $x u$, and if $u \in G$, then $v \notin G$.

B. (transitivity) if $y$ is the midpoint of $x u$ and $z$ is the midpoint of both $y v$ and $x w$, and if $u, v \in G$, then also $w \in G$.

The proof is immediate since no point is both midpoint and endpoint of the same nondegenerate segment.

THeonem 2.2. Let $\delta$ be any antireflexive relation on a set $P$ of cardinality no larger than that of the continuum. Then there exists a subset $G$ of the real line for which the relation $\alpha$ defined by (2.1) is isomorphic to $\delta$.

Proof. Let $f$ be a one-to-one function mapping $P$ into a Hamel basis for $R$. Let

$$
U=\{2 f(q)-f(p): p, q \in P, p \delta q\}
$$

and

$$
G=U \cup 2 f[P] \cup f[P] \cup\{0\} .
$$

For each $p \in P, f(p)$ is the midpoint of the segment $2 f(p) 0$, whose endpoints belong to $G$. Thus $f[P] \subset G^{*}$. If $y \in G^{*}$, on the other hand, then there exist distinct points $x, z \in G$, such that $2 y=z+x$. Also, $y \in G$. Writing $x=c_{1} a_{1}+c_{2} a_{2}$ and $z=c_{3} a_{3}+c_{4} a_{4}$, with $a_{i} \in f[P]$, we have

$$
\begin{aligned}
& c_{1}=2 \text { and } c_{2}=-1 \text { if } x \in U, \\
& c_{3}=2 \text { and } c_{4}=-1 \text { if } z \in U, \\
& c_{2 k-1} \in\{0,1,2\} \text { and } c_{2 k}=0 \text { otherwise. }
\end{aligned}
$$

Assuming now that $y \in U, y=2 a-b$, we have $4 a-2 b=2 y=$ $\sum c_{i} a_{i}$, and since $a \neq b$, (2.4) implies that only $c_{1}=2=c_{3}, a_{1}=a=a_{3}$ 
is possible. But this leads to $c_{2}=-1=c_{4}, a_{2}=b=a_{4}$, and hence to $z=x$, which contradicts our assumption.

The cases $y \in 2 f[P]$ and $y=0$ similarly lead to the conclusion $z=x$. Thus by (2.3) we have $y \in f[P]$, and hence $G^{*} f[P]$.

To see that $f$ is an isomorphism, let $p, q \in P, p \delta q$. Then $x=$ $2 f(q)-f(p)$ is a member of $U \subset G$, and $f(q)$ is the midpoint of the nondegenerate segment $x f(p)$. Thus $f(p) \alpha f(q)$. Conversely, if $z \alpha y$ in $G^{*}=f[P]$, say $z=f(p), y=f(q)$, then $x=2 f(q)-f(p) \in G$ by (2.1). We use (2.3) and the independence of $f[P]$ to show that $x \in U$, and again the independence of $f[P]$ to see that $p \delta q$.

Comment 2.3. An obvious generalization of Theorem 2.2 permits us to represent an arbitrary antireflexive relation in a vector space of sufficiently large dimension over a field of characteristic 5 or larger. Here again " $y$ is the midpoint of $x z$ " means $2 y=z+x, x \neq z$. For characteristic smaller than 5 we might mention that $f[P] \neq G^{*}$.

COROLlary 2.4. Let $P$ be any partially ordered set of cardinal number no larger than that of the continuum. Then there exists a subset $G$ of the real line such that $P$ is isomorphic to the partially ordered set $G^{*}$ of midpoints in $G$.

This follows directly from Proposition 2.1 and Theorem 2.2.

We are now ready to apply Theorem 2.2 to trees. In a slight restatement of 2.1, A becomes: no segment with endpoints in $G$ is trisected by points of $G ; B$ can be summarized by the phrase: $G$ is midpoint transitive. Henceforth we assume that $G$ has these two properties.

Chains in $G^{*}$ are generating subsets of $G^{*}$ in the sense that any two distinct points $x, y$ of a chain generate a segment with endpoints in $G$, one of $x$ and $y$ acting as an endpoint of the segment, the other as the midpoint; i.e. if $u=2 y-x, v=2 x-y$, then $u \in G$ or $v \in G$. We call a subset $X$ of $G^{*}$ segment free (antichain) if every subset of $X$ of cardinality $\geqq 2$ fails to be generating. $X$ is free (from above) in $G$ provided that for any two distict points $x, y \in X$ and any $u, v, z \in G$, $z$ is not the midpoint of both the segments $x u$ and $y v$.

Combining these notions with 2.1 we obtain our main result. Width bounds the cardinality of segment free sets and height that of generating sets in $G^{*}$.

Theorem 2.5. The existence of a Souslin tree is equivalent to the existence of a subset $G$ of the real line whose set $G^{*}$ of midpoints in $G$ is uncountable and satisfies 
1. no segment with endpoints in $G$ is trisected by points of $G$,

2. $G$ is midpoint transitive,

3. segment free subsets of $G^{*}$ are free in $G$,

4. segment free subsets of $G^{*}$ are countable,

5. generating subsets of $G^{*}$ are countable.

Proof. 1. and 2. imply that $\alpha$ is a partial order, by 2.1. 3. is the tree property, and 4. and 5. together with the fact that $G^{*}$ is uncountable make the tree $G^{*}$ into a Souslin tree. Thus the existence of $G$ implies the existence of a Souslin tree, and if a Souslin tree exists, then $G$ exists by 2.4 .

4. In this section we conclude by applying a real line characterization of Souslin's conjecture to obtain a foundations result. In [2] and [3] the continuum hypothesis is shown to be second order determined, i.e.,

$$
\left(\mathscr{L} \vdash_{2} \mathrm{CH}\right) \vee\left(\mathscr{L} \vdash_{2} \sim \mathrm{CH}\right)
$$

where $\mathscr{Z}$ denotes Zermelo's axioms with the axiom of infinity and $\mathrm{CH}$ the continuum hypothesis. The reader is referred to Kreisel and Krivine [3] for a detailed discussion.

A modification of the proof in Kreisel and Krivine applies to Souslin's conjecture:

Proposition 4.1. Souslin's conjecture is second order determined, i.e.,

$$
\left(\mathscr{z} \vdash_{2} S C\right) \vee\left(\mathscr{Z} \vdash_{2} \sim S C\right)
$$

Proof. Let $C_{\omega}$ be the collection of all hereditarily finite sets without individuals, and for $n \in \omega$, let $C_{\omega+n+1}=C_{\omega+n} \cup \mathscr{P}\left(C_{\omega+n}\right)$, where $\mathscr{P}$ denotes the power set. From Proposition 1.1, Souslin's conjecture states that any collection of real sets which under set inclusion forms a tree of countable height and countable width is countable. We may thus canonically formulate Souslin's conjecture as follows:

$$
\begin{aligned}
& {\left[X \subset \mathscr{P}\left(C_{\omega+1}\right) \wedge(x \in X \wedge y \in X \rightarrow x \cap y=\phi \vee x \subset y \vee y \subset x)\right.} \\
\wedge & ((Y \subset X \wedge((x \in Y \wedge y \in Y \rightarrow x \cap y=\phi) \\
\vee & \left.\left.(x \in Y \wedge y \in Y \rightarrow x \subset y \vee y \subset x))) \rightarrow \overline{\bar{Y}} \leqq \overline{\bar{C}}_{\omega}\right)\right] \rightarrow \overline{\bar{X}} \leqq \overline{\bar{C}}_{\omega} .
\end{aligned}
$$

This is expressed by means of quantifiers over $C_{\omega+3}$, since one-to-one correspondences between subsets of $C_{\omega+2}$ are elements of $C_{\omega+3}$. Consequently [3; p. 192] we have $\left(\mathscr{F} \vdash_{2} S C\right) \vee\left(\mathscr{\&} \vdash_{2} \sim S C\right)$. 


\section{REFERENCES}

1. T. Jech, Non-provability of Souslin's Hypothesis, Commentationes Math. Univ. Carolinae, 8 (1967), 291-305.

2. G. Kreisel, Informal Rigour and Completeness Proofs in the Philosophy of Mathematics, Jaakko Hintikka, ed., Oxford Univ. Press, (1969), 78-94.

3. G. Kreisel and J. L. Krivine, Elements of Mathematical Logic, Amsterdam, North Holland Publ. Co., 1967.

4. E. W. Miller, A note on Souslin's problem, Amer. J. Math., 65 (1943), 673-678.

5. G. Miller, On Souslin's problem, Notices Amer. Math. Soc., 16 (1969), 222.

6. M. E. Rudin, Souslin's conjecture, Amer. Math. Monthly, 76 (1969), 1113-1119.

7. M. Souslin, Probleme 3, Fund. Math., 1 (1920), 223.

8. S. Tennenbaum, Souslin's problem, Proc. Nat Acad. Sci. U.S.A., 59 (1968), 60-63.

Received June 1, 1971 and in revised form September 8, 1971. This research was supported by the National Research Council of Canada under Grants A 4796 and A 7571.

UNIVERSITY OF VICTORIA 



\section{PACIFIC JOURNAL OF MATHEMATICS}

\section{EDITORS}

\author{
H. SAMELSON \\ Stanford University \\ Stanford, California 94305 \\ C. R. HOBBY \\ University of Washington \\ Seattle, Washington 98105
}

\author{
J. DugundJI \\ Department of Mathematics \\ University of Southern California \\ Los Angeles, California 90007
}

\author{
RICHARD ARENS \\ University of California \\ Los Angeles, California 90024
}

\section{ASSOCIATE EDITORS}
E. F. BECKENBACH
B. H. NeumanN
F. WOLF
K. YoSHIDA

\section{SUPPORTING INSTITUTIONS}

\author{
UNIVERSITY OF BRITISH COLUMBIA \\ CALIFORNIA INSTITUTE OF TECHNOLOGY \\ UNIVERSITY OF CALIFORNIA \\ MONTANA STATE UNIVERSITY \\ UNIVERSITY OF NEVADA \\ NEW MEXICO STATE UNIVERSITY \\ OREGON STATE UNIVERSITY \\ UNIVERSITY OF OREGON \\ OSAKA UNIVERSITY
}

\author{
UNIVERSITY OF SOUTHERN CALIFORNIA \\ STANFORD UNIVERSITY \\ UNIVERSITY OF TOKYO \\ UNIVERSITY OF UTAH \\ WASHINGTON STATE UNIVERSITY \\ UNIVERSITY OF WASHINGTON \\ $* * * *$
$*$
AMERICAN MATHEMATICAL SOCIETY
NAVAL WEAPONS CENTER
}

The Supporting Institutions listed above contribute to the cost of publication of this Journal, but they are not owners or publishers and have no responsibility for its content or policies.

Mathematical papers intended for publication in the Pacific Journal of Mathematics should be in typed form or offset-reproduced, (not dittoed), double spaced with large margins. Underline Greek letters in red, German in green, and script in blue. The first paragraph or two must be capable of being used separately as a synopsis of the entire paper. The editorial "we" must not be used in the synopsis, and items of the bibliography should not be cited there unless absolutely necessary, in which case they must be identified by author and Journal, rather than by item number. Manuscripts, in duplicate if possible, may be sent to any one of the four editors. Please classify according to the scheme of Math. Rev. Index to Vol. 39. All other communications to the editors should be addressed to the managing editor, Richard Arens, University of California, Los Angeles, California, 90024.

50 reprints are provided free for each article; additional copies may be obtained at cost in multiples of 50 .

The Pacific Journal of Mathematics is published monthly. Effective with Volume 16 the price per volume (3 numbers) is $\$ 8.00$; single issues, $\$ 3.00$. Special price for current issues to individual faculty members of supporting institutions and to individual members of the American Mathematical Society: $\$ 4.00$ per volume; single issues $\$ 1.50$. Back numbers are available.

Subscriptions, orders for back numbers, and changes of address should be sent to Pacific Journal of Mathematics, 103 Highland Boulevard, Berkeley, California, 94708.

PUBLISHED BY PACIFIC JOURNAL OF MATHEMATICS, A NON-PROFIT CORPORATION

Printed at Kokusai Bunken Insatsusha (International Academic Printing Co., Ltd.), 270, 3-chome Totsuka-cho, Shinjuku-ku, Tokyo 160, Japan. 


\section{Pacific Journal of Mathematics}

\section{Vol. 43, No. 2 \\ April, 1972}

Arne P. Baartz and Gary Glenn Miller, Souslin's conjecture as a problem on the real line....................................... 277

Joseph Barback, On solutions in the regressive isols ............... 283

Barry H. Dayton, Homotopy and algebraic K-theory ................ 297

William Richard Derrick, Weighted convergence in length ............ 307

M. V. Deshpande and N. E. Joshi, Collectively compact and semi-compact sets of linear operators in topological vector spaces ............. 317

Samuel Ebenstein, Some $H^{p}$ spaces which are uncomplemented in $L^{p} \ldots . .327$

David Fremlin, On the completion of locally solid vector lattices ......... 341

Herbert Paul Halpern, Essential central spectrum and range for elements of

a von Neumann algebra............................... 349

G. D. Johnson, Superadditivity intervals and Boas' test ............. 381

Norman Lloyd Johnson, Derivation in infinite planes . . . . . . . . . . . 387

V. M. Klassen, The disappearing closed set property .............. 403

B. Kuttner and B. N. Sahney, On the absolute matrix summability of Fourier series ........................................... 407

George Maxwell, Algebras of normal matrices................... 421

Kelly Denis McKennon, Multipliers of type $(p, p) \ldots \ldots \ldots \ldots \ldots \ldots . . \ldots 29$

James Miller, Sequences of quasi-subordinate functions ............. 437

Leonhard Miller, The Hasse-Witt-matrix of special projective varieties ..... 443

Michael Cannon Mooney, A theorem on bounded analytic functions ...... 457

M. Ann Piech, Differential equations on abstract Wiener space .......... 465

Robert Piziak, Sesquilinear forms in infinite dimensions ............. 475

Muril Lynn Robertson, The equation $y^{\prime}(t)=F(t, y(g(t))) \ldots \ldots \ldots \ldots .483$

Leland Edward Rogers, Continua in which only semi-aposyndetic

subcontinua separate ............................... 493

Linda Preiss Rothschild, Bi-invariant pseudo-local operators on Lie

groups ...................................... 503

Raymond Earl Smithson and L. E. Ward, The fixed point property for

arcwise connected spaces: a correction ...................... 511

Linda Ruth Sons, Zeros of sums of series with Hadamard gaps .......... 515

Arne Stray, Interpolation sets for uniform algebras............... 525

Alessandro Figà-Talamanca and John Frederick Price, Applications of random Fourier series over compact groups to Fourier multipliers .. 